DOI 10.37882/2223-2982.2020.07-2.06

\title{
МЕТАФОРИЧЕСКИЕ НОМИНАНТЫ СО ЗНАЧЕНИЕМ ОТРИЦАТЕЛЬНОЙ ЭТИЧЕСКОЙ ОЦЕНКИ В ДРЕВНЕРУССКОМ ЯЗЫКЕ
}

\section{METAPHORICAL NOMINANTS WITH A MEANING OF A NEGATIVE ETHICAL ASSESSMENT IN OLD RUSSIAN LANGUAGE}

\section{A. Vasilieva}

Summary: The article is devoted to the study of metaphorical nominants expressing a negative ethical assessment in the Russian language of the $\mathrm{XI}$ XIV centuries. The task is to analyze a certain layer of the corresponding predicates, to identify patterns of occurrence of secondary abstract meanings in these lexemes, and to give them a cultural commentary. During the study, methods of description, semantic and component analysis were used. The work may be of practical importance for the development of research methods in the field of historical semantics, sociolinguistics and linguocultural studies.

Keywords: meaning, sema, assessment, concept, metaphorical nominant, semantic derivation model, Old Russian language. $\ni$ волюция метафоричности слова напрямую связана с развитием языковой категории абстрактности. Изучение процессов семантической деривации показывает, как менялись абстрактные категории в языке, какие трансформации претерпевали ценностные и познавательные ориентиры в лингвокультуре, поскольку метафора, вместе с метонимией, «являются важнейшими механизмами когнитивной деятельности и регулируют функционирование единиц лексического и ментального уровней, выступающих в роли средств моделирования категорий отвлеченности и абстрактности» [11].

Диахронический аспект метафорической деривации в русском языке разработан лишь отчасти. Динамику метафорических моделей в русской лингвокультуре, начиная с XI века, проследила, к примеру, О.Н. Кондратьева в своем диссертационном труде [8]. Анализ метонимической и метафорической деривации на материале средневековых памятников русской деловой письменности провела И.М. Некипелова [11]. Хорошо известны также работы в области исторической семантики Н.Ф. Алефиренко, В.В. Колесова, Д.С. Лихачева, Г.Н. Лукиной, П.И. Мельникова, Т.М. Николаевой, Л.С. Андреевой, Г.И. Белозерцева и других. Подробно исследовала метафору в диахроническом аспекте Л. В. Балашова [3; 4; 5]. Однако отдельных работ, посвященных вопросу реализации
Васильева Анастасия Юрьевна

аспирант, Башкирский государственный университет

(2. Уфрa)

anastasija888555@yandex.ru

Аннотация: Статья посвящена изучению метафорических номинантов, выражающих негативную этическую оценку, в русском языке XI—XIV веков. В работе ставятся задачи проанализировать определенный пласт соответствующих предикатов, выявить модели возникновения вторичных абстрактных значений у данных лексем и дать им культурологический комментарий. В ходе исследования были использованы методы описания, семантического и компонентного анализа. Работа может иметь практическую значимость для разработки методик исследований в области исторической семантики, социолингвистики и лингвокультурологических изысканий.

Ключевые слова: значение, сема, оценка, концепт, метафорический номинант, модель семантической деривации, древнерусский язык.

значения этической оценки у метафорических номинантов русского языка в диахронии, пока не было. Этим фактором обусловлена актуальность настоящей работы. Научная новизна определяется тем, что процессы и результаты метафорической деривации в древнерусском языке рассматриваются в аксиологическом аспекте, в рамках антропоцентрической парадигмы в науке.

Получив способность рефлексировать, человек обретает возможность и потребность так или иначе оценивать окружающую ситуацию относительно своего представления о благе. В языке, отражающем сознание говорящего, существуют два полюса оценки - ХОРОШО и ПЛОХО. Данная оппозиция является одной из базовых корреляций в человеческом сознании. Визуализировать все многообразие аксиологических понятий можно в виде координатной плоскости. Причем функция, скорее всего, никогда не обретает нулевое значение. Мы имеем в виду способы выражения нейтральной оценки в языке. Данная проблема в лингвистике до сих пор не решена. В определении категории оценки большинство ученых сходится во мнении, что она всегда несет в себе знак «+» или «-». Например, Т.В. Маркелова дает такую трактовку: «Языковое содержание категории оценки представляет собой оценочный признак, специфика которого - приписывать предмету речи признак положительного или 
отрицательного ценностного отношения к нему субъекта» $[10$, с. 108]. В «Словаре лингвистических терминов» О.С. Ахмановой находим, что оценка - это: «Суждение говорящего, его отношение - одобрение или неодобрение, желание, поощрение и т. п. - как одна из основных частей стилистической коннотации» [2, с. 305]. В то же время существуют работы, посвященные вопросу реализации нейтральной оценки в языке. О ней пишет, например, М.В. Головня [7], хотя, по всей видимости, также приходит к выводу о том, что любая оценка, в зависимости от контекста, стремится к положительному либо отрицательному полюсу. Отметим, что на наш взгляд, существующие в языке предикаты, помещенные в центре оценочной системы координат (вроде лексем нормальный, обычный, рядовой), так или иначе, выражают удовлетворение или неудовлетворение говорящего оцениваемой им ситуацией.

Понятия ХОРОШИЙ и ПЛОХОЙ относят к общеоценочным [1]. Они не несут в себе конкретизации, объяснения оценки, являясь некими абсолютами в аксиологической системе. Вместе с тем они относительны, поскольку понимание того, что хорошо, а что плохо, для всех разное. Эти понятия составляют основу семантики всех остальных оценочных предикатов, отличающихся, по сути, наличием мотивировки, объяснением присвоения знака «плюс» или «минус»: честный = 'хороший, потому что не обманывает'; трусливый = 'плохой, потому что не может преодолеть страх', полезный ='хороший, потому что приносит благо' и т.д. Иными словами, во всех частнооценочных номинантах будет присутствовать «базовая» оценка, а к ней уже присоединяются обоснования и, возможно, различного рода коннотации, оттенки (например, презрения, нежности, иронии и т.д.). Исходя из данных соображений, считаем целесообразным в исследовании оценочных номинантов отталкиваться от предикатов общей оценки.

В настоящей статье мы решили рассмотреть адъективы с общеоценочным значением 'плохой', возникшим в результате метафорической деривации. Для этого были использованы результаты фундаментального труда И. И. Срезневского «Материалы для словаря древнерусского языка по письменным памятникам» [13], с привлечением дополнительных источников. Итак, значение 'плохой' было широко представлено в языке XI - XIV веков; его, например, выражали такие прилагательные как ЗЪЛыИ, ЛИХЫИ, СКВЬРНЫИ, СКВЬРНЬНЫИ, СКУДЬНЫИ, СКЬРБЬНЫИ, ТЪЩИИ, ХУДЫИ, НЕСАМООБРАЗЬНЫИ, ОСКЪРБЬНЫИ. Подобная тенденция актуализации негативной оценки скорее лингвистическая универсалия, так как отклонения от нормы находятся в фокусе внимания носителей языка. Н.Д. Арутюнова отмечает, что: «Восприятие мира <...> прежде всего фиксирует аномальные явления» [1, c. 304]. Также очевидно, что для развития отрицательнооценочной семантики в языке средневековой Руси се- рьезным стимулом становится развитие православной культуры, что напрямую влияло на жанрово-стилистическую направленность текстов (мы имеем в виду расцвет таких жанров как Поучение, Слово, Моление и т.д.). Закономерные изменения претерпевает орудие авторской мысли - язык. Это время активных словообразовательных процессов, греческих калькирований и метафорического переосмысления действительности.

Рамки статьи не позволяют охватить все номинанты со значением отрицательной оценки, в связи с этим для анализа мы решили взять лексемы с эквивалентной первичной семантикой, поскольку, как известно, «слова со сходным значением проходят сходную семасиологическую историю» [12, с. 80]. Научный интерес для характеризации особенностей деривационных процессов, происходивших в русском языке, представляют номинанты с исходным конкретным количественным значением, такие как ХУДыИ, ТъЩИИ, СКУДьНыИ.

Прилагательное Х8ДыИ в древнерусском языке обнаруживает ряд значений:

1. 'плОхой, дУрной': НА ХОУДБ ПОСТЕЛИ ОУПОЧИВАТИ И ХОУДОЮ ОДЕЖЕЮ ФДЬВАТИСА НА ЛОЖИ ВЪ КЕЛЬИ СВОЮИ 'На плохой постели спать и плохо одеваться на ложе в своей келье'

2. 'некрасивый, невзрачный': БЫ ХОУДъ ЛИЦЕМъ И НРАВОМЪ ЧЮДЕНЪ 'БыЛ дурен лицом и с нравом странным'

3. 'некрепкий, непрочный': Х४ЖЕ ПАОУЧИНЫ'тоньше паутины'

4. 'слабый': ... НО ХОУДъ ЮСМЬ И БОЛЕНъ '... но я слаб и болен'

5. 'МалЫЙ': ВЪДОВИЦА ДА ВЪЧИНАЮТЬСА, НЕ ХВЖДЕ ЛЬТЪ ШЕСТИДЕСАТЪ БЫВЪШИ ОУ ЮДИНОГО МОУЖА 'Вдовица <церковное звание - прим. авт.> должна быть избираема не менее, как шестидесятилетняя, бывшая женою одного мужа'

6. 'бедный, скудный': РБКА СТУГНА, ХУДУ СТРУЮ ИМちЯ, ПОЖРЪШИ ЧУЖИ РУЧЬИ <и стругы, рострена къ усту> 'Река Стугна, маловодная сама по себе, поглотив (в половодье) другие ручьи и потоки, расширена / сужена (стиснута берегами) [9] к устью' [перевод там же, с. 896].

7. 'бедный, в бедности находящийся': $B Ъ$ СВЖДАЛЬСКОИ ЗЕМЛИ ГОЛОДЬ БАШЕ, МНОЗИ ХОУДИИ ИДАХОУ В НОВГОРОДЬСКОУЮ ВОЛОСТЬ КОРМИТЬСА 'Был голод в земле Суздальской, многие бедняки пошли в Новгородскую волость за пропитанием'

8. 'незнатный, простой': И ХУДАГО СМЕРДА, И ОУБОГЫЪ ВДОВИЦБ НЕ ДАЛЬ ЮСМЪ <СИЛЬНЫМъ> ФБИДちТИ 'И простого смерда, и убогую вдову сильным не дал я в обиду'

9. 'незначительный, не обладающий достоинствами' 10. 'дурной, скверный, зловредный': ЗЪЛъ <чловекъ> 
ТЪЩАСА НА ЗЛОЮ НЕ ХУЖЕШИ ЮСТЬ ББСА 'ЗЛОЙ человек со скверными намерениями не отличается от беса'

11. 'жалкий'

12. 'нИчтожнЫЙ': НО ТЫ САМЪ ДЕРЖАВЬНУЮ РУКУ ТВОЮ ПРОСТРИ НА МА ГРБШЬНАГО И ХУДАГО 'НО ты сам протяни ко мне, грешному и ничтожному, руку твою державную; АЗЪ ХУДЫИ, ГРБШНЫИ, НЕДОСТОИНЫИ НАЧИНАЮ ПИСАТИ ЖИТЬЕ ВЕЛИКОГО КНЯЗЯ ОЛЕКСАНДРА'Я, ничтожныЙ, грешный, недостойный, начинаю жизнеописание великого князя Александра'

13. 'слабый, безличный': НБКОЕМУ УБО У НИХъ ХУДУ ЦАРЮЮЩУ, А ВСЕ ДЬЮЩЮ У НИХЪ КНЯЗЮ МАМАЮ (противопоставление слабого формального правителя и фактической власти)

14. 'неясный' [13, т. 3, стб. 1414-1420].

В первых шести случаях мы видим проявления физической оценки, то есть реализации конкретных значений. Очевидно, что они являются основными для лексемы ХУДыИ и напрямую связаны с изначальной семантикой соответствующего корня, которую исследователи сближают с понятиями 'маленький', 'убогий', 'недостаточный' и т.п. [15, с. 111-113]. В 7 и 8 случае ХУДЫИ представлено в значении социальной оценки. В 9, 11 и 13 лексема обретает значение интеллектуальной характеристики. А в 10 и 12 мы наблюдаем реализацию значения этической оценки.

Последнее значение, как и остальные производные у данной лексемы, образовалось в результате метафорической деривации. Языковая реализация количественного обозначения физических понятий переносится на явления этической сферы. Недостаток в чем либо - не только отклонение от нормы, но и угроза благополучию конкретного человека или общества. Соответственно, то, что противоречит человеческому пониманию блага, воспринимается отрицательно. С развитием абстрактных категорий возникает необходимость языкового выражения понятий морали и нравственности, и для решения этой задачи человек использует уже готовые и опробованные языковые средства. Одно из проявлений такой деятельности - метафорическая деривация. С одной стороны, это демонстрация лингвистической экономии, а с другой, - свидетельство высокого уровня отвлеченно-образного мышления.

Модель 'отрицательное количество $\rightarrow$ отрицательное этическое качество' реализуется не только в лексеме ХУДЫИ соответствующего словарного гнезда, но и в других его членах, например: ХвДИТИ 'охуждать, осуждать'; Х8ДОВБРИЮ 'маловерие'; Х8ДОВБРЬНЫИ 'неверующий'; ХВДОГЛАГОЛАНИЮ 'мелОчность'; ХВДОДВШЬНЫИ 'малодушный'; Х8ДОД8ШЬСТВОВАТИ'малодушествовать'; Х8Дち 'жестоко' [13, т. 3, стб. 1414-1420]. В последней лексеме Х8Дち, имеющей также значения 'плохо, худо', 'мало, 'ни мало, нисколько', отображается, как языковое обозначение количества ('мало') используется для выражения оценки физического ('плохо, худо') и морального качества ('жестоко').

В некоторых лексемах трудно разграничить этическую и другие виды оценок, поскольку они проявляют некое смысловое единство в определенном контексте:

- синкретизм физической и этической оценки: ХВДОЛАЖА 'нИчтоЖный': ИЛИ АЗЪ ЮСМЬ ЗБЛО НЕМОЩЬНЪ И ГРБШЬНЪ И ХОУДОЛАЖА 'Или Я очень немощен, грешен и ничтожен'

- синкретизм этической и интеллектуальной оценки: ХВДОРАЗВМЬНЫИ 'неразумный': СЛО-

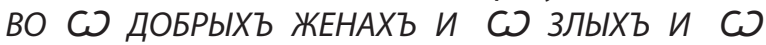
ХОУДОРАЗОУМНЫ<хъ>: 'Слово о хороших женщинах, и плохих, и неразумных' [13, т. 3, стб. 14141420].

Аналогичный семантический путь проходит и лексема ТЪЩИИ (= ТОЩИИ = ТЩИИ). Изначально реализующая конкретное количественное значение, связанное с отсутствием или недостатком чего-либо, она становится средством выражения различных категорий оценки:

- интеллектуальной: ТЪЩИИ 'пустой, бессодержательный' (БУДУ ЯКО КРУГъ МБДЯНъ, ТЩИМъ ГЛАСОМъ БРЯЦАЯ - 'Буду подобен медному кругу, пустыми словами звеня');

- утилитарной: ТЪЩИИ 'плохой' (НЕ ТЪЩЮ, НЪ ДОБРОУ ИМБТИ ВЕЩЬ - противопоставление «плохой» и «хорошей» вещи);

- телеологической: ТЪЩИИ 'пустой, напрасный';

- этической: ТЪЩИИ 'суетный' (ТЪШТАЯ РАДИ СЛАВЫ - о тщеславии) [13, т. 3, стб. 1064-1065].

Первоначальное значение лексемы ТЪЩИИ сохраняется и активно используется в древнерусском языке: 'с пустыми руками, ничего не имеющий в руках (в прямом и переносном значении)' (САМъ БО ГОСПОДЬ МОИСІОМъ ГЛАГОЛЕТЬ: НЕ ЯВЛЯИСЯ ПРЕДЪ МНОЮ ТЪЩЬ ВЪ ДЕНЬ ПРАЗДНИКА - 'Сам господь говорит Моисею: не являйся предо мною с пустыми руками в праздничный день');'ничтожный' (МОЩь ИХЪ ТОЩА ЮСТЬ - 'Сила их ничтожна'). Также ср., например, однокоренную лексему ТъЩИНА 'убыток' (БЫСТЬ ТЪЩИНА ВЕЛИЯ ПРОДАЮЩИМЪ СОЛЬ, ИЖЕ (ВМесто ОЖЕ) ПРЕЖЕ ЦБНЯШЕ ПО <2> ГОЛВАЖИ НА К8Н8, НЫНБ ЖЕ И ПО <10> НЕ ОБРБТОМБ) [13, т. 3, стб. 1064-1065].

Сближается с лексемами ХУДыИ и ТъЩИИ прилагательное СКвДьНЫИ (СКДДьНЫИ). Имея тождественное им первичное количественное значение, оно сохраняет его и в древнерусском языке: 'недостаточный', 'нуждающийся', 'бедный' (ОДБЯНІЕМъ ЕСМЬ СКУДЕНЪ, НО РАЗУМОМЪ ОБИЛЕНЪ - 'Нарядом я беден, но разумом 
богат' - прим. из «Слова Даниила Заточника»); 'редкий'; 'незначительный, ничтожный'. Также выделяется еще одно, не окончательно определенное, значение 'неясНЫЙ': БЫ ЗНАМЕНИЕ В ЛУНБ СТРАШНО И ДИВНО:.. ВСА ПОГИБЕ, ИБЫ СББРАЗЪ ЕЯ ЯКО СКУДНО ЧЕРНО -'БЫЛО ЛУНнОе затмение страшно и удивительно:.. она вся исчезла, и был ее образ смутно-черным'[13, т. 3, стб. 394-396].

Но мы бы не упомянули данный номинант, если бы оно не обнаруживало реализации общеоценочной семантики: СКВДЬНЫИ 'худой, плохой' (БРАНЬ СЛАВНА ЛОУЧЕ МИРА СКУДНА - 'Славная война лучше плохого мира'). Данное значение также возникает в результате семантической деривации. Но судя по всему, здесь значение «плохой» возникает, скорее всего, контекстуально, так как в остальных представителях словообразовательного гнезда оно не встречается. Проанализированные нами лексемы (СКВДЫИ/СКЖДЫИ, СКВДО, СКВДЬНО, СКВДОСТЬ, СКВДОТА/СКЖДОТА, СКВДЬСТВО, СКВДЬСТВОВАТИ, СКВДОБРАДЫИ, СКВДОВМЬСТВО, СКВДЬНОВМЬНЫИ/СКЖДЬНОВМЬНЫИ [13, т. 3, стб. 394396]) несут в себе семы материального, физического или ментального недостатка - нужды, воздержания, бедности.

Интересно то, что в современном русском языке представленные лексемы утрачивают свои вторичные значения и «возвращаются» к выражению исключительно количественных характеристик физических свойств, сохраняя аксиологическую семантику в архаизмах или устойчивых сочетаниях (На худой конец - пример авт.). Функцию реализации общей и частной отрицательной оценки принимают на себя другие лексемы, такие как плохой, ужасный, отвратительный и т.д.

Представленные примеры демонстрируют продуктивность деривационных моделей «мало $\rightarrow$ плохо». То есть недостаток в чем-либо традиционно оценивается негативно. Однако отрицательную оценку получают проявления не только нехватки, но и излишества. Вот что пишет по этому поводу Ж. Вардзелашвили: «Метафорические номинации пейоративной оценки обнаруживают большое семантическое разнообразие и языковую устойчивость: отрицательно оцениваются пороки (глупость, равнодушие, жестокость и т.п.), неблаговидное, недостойное поведение (чванство, притворство и т.п.), низкое общественное положение, физические недостатки, а также некоторые физические качества, объективно не являющиеся отрицательными, но обладающие избыточностью, чрезмерным проявлением (чрезмерная худоба, чрезмерная полнота, чрезмерно высокий рост и т.п.):)» [6].

Ярким примером тому служит прилагательное ЛИХЫИ. Его производное значение 'плохой' образовалось по той же модели, что и у ХУДЫИ, ТъщИИ, СКВДНЫИ, притом, что первичное было прямо противоположным. Его мы наблюдаем как у самой лексемы ЛИХыИ, так и у членов его словообразовательного гнезда: ЛИХЫИ 'излишний, больший'; 'чрезмерный, чрезвычайный'; ЛИХВА 'лихва, рост, процент'; ЛИХОЮ 'избыток' (РОСТЪ И ЛИХОЕ ВЪЗИМААХЖ ВЪ ТЕББ - 'Прибыль и излишек взимали у тебя'); ВЪ ЛИХОТЬ 'излишне'; ИЗЪ ЛИХА 'больше', 'более, особенно', 'очень, чрезвычайно' (КРБПЪКЪ ИЗЪ ЛИХА 'Чрезвычайно крепкий') [13, т. 1, стб. 25-30].

Вместе с тем производное значение этической оценки, имеющее метафорическую природу, широко используется в текстах: ЛИХЫИ 'дурной, злой' (ЗЪ ДОБРЫМъ БО ДУМЪЦЕЮ КНЯЗЬ ВЫСОКА СТОЛА ДОДУМАЕТЦА, А СЪ ЛИХИМЪ ДУМЪЦЕЮ ДУМАЕТЪ, И МАЛАГО СТОЛА ЛИШЕНЪ БУДЕТЪ (из «Слова Даниила Заточника») - 'С благой думой князь достигнет высокого престола, а с дурной и малого престола лишится'. АЖЕ ОУЧИНИТЬ РОУСИНЪ НАСИЛЬЕ... НАДЪ ВОЛЬНОЮ ЖЕНОЮ, А ДОТОЛЕ НЕ СЛЫШАТИ БЫЛО ДО НЕЕ ЛИХОГО, ОУРОКА ЗА ТО .. < <10> <грИвенъ > СБРББРА - 'Если совершит русский насилие над свободной женщиной, о которой до того не было дурной славы, то получит штраф 10 гривен серебром' (из Смоленской грамоты 1230 г - проект договора Смоленска с немцами половины XIII века) [13, т. 1, стб. 25-30]).

Высокая продуктивность модели 'много' $\rightarrow$ 'плохо' демонстрируется и в других образованиях соответствующего корня: ЛИХОДБИ 'лиходеи, злодеи'; ЛИХОДБЛЬНИЦА: БЛОУДЬНИЦА ИЛИХОДБЛЬНИЦА, <глаголюшта> НЕПОДЪБЬНАЯ); ЛИХНОВЬНОЮ 'грех, порок, ошибка' (ЛИХНОВЬНОЮ ЖЕ ЮСТЬ РБЧЬ ЛИШИТИ ИСТИНЫ ВЪЗДРАШТЕНИЯ РАДИ); ЛИХНОВЬЦЬ'ДЬЯВОЛ'; ЛИХОТЪНЫИ ‘беспорядочный, беспутный' и др. [13, т. 1, стб. 25-30].

Во многих номинантах прослеживается определенный семантический синкретизм. К примеру, такие синонимы как ЛИХОИМьНИКъ, ЛИХОИМАНЬНИКЪ, ЛИХОИМьЦь 'лихоимец' (МьЗДОИМьЦь, ТИ лИХОИМьЦь, ТИ СРЕБРОЛЮБЬЦЬ - 'Мздоимец, ты лихоимец, ты сребролюбец' [13, т. 1, стб. 25-30]), с одной стороны, сохраняют семантическую мотивированность, а с другой стороны, выражают этическую оценку (лихоимец, по Ушакову, это человек, «берущий слишком большие поборы или проценты; взяточник, ростовщик» [14]).

Однако, интересно то, что в отдельных случаях наличие в слове дает положительную коннотацию: ЛИХОИМъ 'обилующий, богатый' (АФОНАСІИ ВЕЛИКЫИ ЛИХОИМЪ БЛАГОНРАВІИ); ЛИХОМУДРЫИ (О ЛИХОМОУДРОМЪ ЕВРУКЛЬИ - 'О премудром Евруклии'). Есть и совершенно уникальные примеры отражения в одной лексеме противоположных смыслов: ЛИХНОВИЦА 'избыток', 'превосходство, преимущество', 'распутство'; ЛИХНВТИ 'превзойти'; 'преступить, согрешить'. Такие примеры как ЛИХВОВАТИ 'обижать', 'давать в рост'; ЛИХНОВЕНИЮ 'из- 
лишество, преступление' ([13, т. 1, стб. 25-30]), наряду с вышеперечисленными, дают ценную информацию о ценностных ориентирах общества средневековой Руси, а именно: негативном отношении ко всякого рода излишествам, порицании стяжательства и ростовщичества, осуждения чрезмерного богатства и превышения допустимых норм.

Таким образом, мы провели анализ предикатов со значением этической оценки, образованным в результате метафорической деривации, выявили модели возникновения вторичных абстрактных значений у номинантов с эквивалентным первичным количественным значением и попытались осмыслить причины и результаты данных процессов. Выяснилось, что метафорические номинанты со значением отрицательной этической оценки демонстрируют высокую степень продуктивности в древнерусском языке. Помимо объективных (психолингвистических, когнитивных) причин, дополнительным фактором такого явления в языке XI-XIV веков послужила дидактическая направленность памятников письменности средневековой Руси. Расцвет православной культуры, византийское литературное наследие определили характер, жанрово-стилевую направленность, отраженную в особом поучительном тоне повествования, направленном на порицание пороков. Отсюда и высокая продуктивность определенных словообразовательных моделей, развитые синонимичные отношения предикатов этической сферы с отрицательной оценкой. Также мы подтвердили, что единство основной семы - в конкретном случае количественной - определило тождество эволюции значения.

Перспективы данного исследования мы видим в расширении как его материала, так и диахронических рамок: научный интерес представляет комплексное изучение эволюции метафорических номинантов этической оценки в XIV-XVII веках, в Новое время и, конечно, в современном русском языке, а также определение тенденций их дальнейшего развития.

\section{ЛИТЕРАТУРА}

1. Арутюнова Н.Д. Типы языковых значений: Оценка. Событие. Факт. М.: Наука, 1988. 341 с.

2. Ахманова 0.С. Словарь лингвистических терминов. М., 2005. С. 305.

3. Балашова, Л.В. Когнитивный тип метафоры в диахронии (на материале перцептивной лексики русского языка) [Текст] / Л. В. Балашова // Филология. Саратов, 1999. Вып. 4. С. 27-37.

4. Балашова, Л.В. Метафора в диахронии (на материале русского языка XI-XX вв.) [Текст] / Л. В. Балашова. Саратов : Изд- во Сарат. ун-та, 1998. 217 с.

5. Балашова, Л.В. Роль метафоризации в становлении и развитии лексико-семантической системы (на материале русского языка XI-XIV вв.) : дис. ... д-ра филол. наук: 10.02.01 [Текст] II Л. В. Балашова. Саратов, 1999. 420 с.

6. Вардзелашвили, Ж. Метафорическая картина мира в русском языке: автореф. дис... . д-ра филол. наук. 10.02.03 [Текст] / Ж. Вардзелашвили. Тбилиси, 2002. 40 c. [Электронный ресурс] Режим доступа: http://vjanetta.narod.ru/ref.html

7. Головня М.В. Средства выражения нейтральной оценки (на примере произведений А.Т. Твардовского) // Вестник Московского государственного областного университета. Серия: Русская филология. 2010. № 1. с. 62-65.

8. Кондратьева 0.Н. Динамика метафорических моделей в русской лингвокультуре: XI - XX вВ.: автореф. дис.... д-ра филол. наук. 10.02.01 [Текст] / 0.H. Кондратьева. Екатеринбург, 2014. 46 с. [Электронный ресурс] Режим доступа: https://www.dissercat.com/content/dinamika-metaforicheskikh-modelei-vrusskoi-lingvokulture-xi-xx-vv (дата обращения: 21.05.2020).

9. Максимов В.И. Стугна и Днепр или История утопления юного князя Ростислава, брата Мономахова (по тексту «Слова о полку Игореве»)// Герменевтика древнерусской литературы: Сборник 16-17. Российская академия наук; Ин-т мировой литературы им. А.М. Горького; отв. ред. М.В. Первушин. М., 2014. C. 886-897

10. Маркелова Т.В. Оценка и оценочность // Семантическая структура слова и высказывания: Межвузовский сборник научных трудов. М., 1993. С. 108.

11. Некипелова, И.М. Метонимическая и метафорическая деривация в истории русского языка: На материале памятников деловой письменности XI-XVII веков: автореф. дис.... канд. филол. наук. 10.02.01 [Текст] / И.М. Некипелова. Казань, 2005. 24 с. [Электронный ресурс] Режим доступа: https://www. dissercat.com/content/metonimicheskaya-i-metaforicheskaya-derivatsiya-v-istorii-russkogo-yazyka-na-materiale-pamуa (дата 0бращения: 19.05.2020).

12. Покровский М.М. Избранные работы по языкознанию / М.М. Покровский. М.: Изд-во Юрайт, 2018. 378 с.

13. Срезневский, И.И. Материалы для словаря древнерусского языка по письменным памятникам / И.И. Срезневский. СПб.: Издание Отделения русского языка и словесности Императорской АН, 1893. Т. 1. 1420 с.; 1902. Т. 2. 1802 с.; 1912. Т. 3.1684 с; дополнения. 272 с.

14. Толковый словарь русского языка: [В 4 т.] / Под ред. Д.Н. Ушакова. Т. 2: Л-Ояловеть / Сост. В.В. Виноградов и др.; Гл. ред. Б.М. Волин, Д.Н. Ушаков. М.: Изд. центр Терра, 1996.

( Васильева Анастасия Юрьевна (anastasija888555@yandex.ru). 